\title{
A Study of Mesh Sheets of 3-kW Stirling Engine Takeshi Enomoto ${ }^{1}$, Atsushi Matsuguchi ${ }^{2}$, Noboru Kagawa ${ }^{3}$ \\ ${ }^{1}$ National Defense Academy \\ 1-10-20 Hashirimizu, Yokosuka, 239-8686 JAPAN, em59023@nda.ac.jp \\ ${ }^{2}$ National Defense Academy \\ 1-10-20 Hashirimizu, Yokosuka, 239-8686 JAPAN, matsu@nda.ac.jp \\ ${ }^{3}$ National Defense Academy \\ 1-10-20 Hashirimizu, Yokosuka, 239-8686 JAPAN, kagawa@nda.ac.jp
}

Keywords: Stirling engine, Regenerator, Mesh sheet.

\begin{abstract}
In recent years, the interest in low-pollution and high-efficiency heat engines has been increasing due to the growing awareness of environmental protection, and power generation at relatively low temperatures, such as use of exhaust heat and sunlight, has been attracting attention. Compared with other heat engines, Stirling engine is very important because it can be driven by any heat source at low temperatures, such as exhaust heat, and it does not emit exhaust gas. In order to realize a more efficient Stirling engine, it is essential to design a heat exchange system that is suitable for each component.

Performance measurement and analysis on a new mesh regenerator material at low temperature difference using a 2-piston alpha-type 3-kW Stirling engine, NS03T are carried out. Mesh sheets developed for high performance Stirling engines can be designed with CAD and CAM technologies by etching process. For this study, M5 and M7 mesh sheets which are thin sheets of stainless steel with square holes in a grid arrangement, are used. With nitrogen and helium as the working fluid, the engine performance is measured by changing the charge pressure, heating temperature, and engine speed to clarify the flow resistance and heat transfer characteristics of the M5 and M7.
\end{abstract}

\section{NOMENCLATURES}

$\begin{array}{llllll}d & : & \text { distance, depth } & \eta & : & \text { efficiency } \\ d_{m} & : & \text { diameter of wire } & \sigma & : & \text { specific surface area } \\ l & : & \text { opening } & \phi & : & \text { porosity } \\ n & : & \text { engine speed } & \nu: & \text { kinematic viscosity coefficient } \\ P & : & \text { pressure } & N: & \text { number of stacked sheets } \\ p & : & \text { pitch } & \rho: & \text { density } \\ Q & : & \text { quantity of heat } & T: & \text { temperature } \\ t & : & \text { thickness } & c_{p}: & \text { constant pressure specific heat } \\ W & : & \text { power } & \lambda: & \text { thermal conductivity of working fluid } \\ w & : & \text { width } & w_{i}: & \text { instantaneous mass flow rate } \\ V & : & \text { volume } & \text { opening area ratio } & & \end{array}$




\begin{tabular}{ccl}
\multicolumn{2}{l}{ Subscripts } & \\
$C$ & $:$ & cooler \\
$c$ & $:$ & compression \\
$c c$ & $:$ & compression cylinder \\
$e$ & $:$ & expansion \\
$e c$ & $:$ & expansion cylinder \\
eff & $:$ & effective \\
$g$ & $:$ & groove \\
ind & $:$ & indicated
\end{tabular}

$\begin{array}{lll}\text { mean } & : & \text { mean } \\ \text { out } & : & \text { output } \\ p & : & \text { pressure } \\ \text { total } & : & \text { total } \\ \text { rloss } & : & \text { regenerator loss } \\ x & : & \text { direction in } \mathrm{x} \\ y & : & \text { direction in } \mathrm{y}\end{array}$

\section{INTRODUCTION}

With an aid of heat-recovery mechanism between two isochoric processes of a Stirling cycle, the cycle efficiency, so-called indicated efficiency becomes higher and improves the total thermal efficiency. The heat-recovery mechanism, so called regenerator, plays a very important role in Stirling cycle machines. If a regenerator of a Stirling engine works ideally, required heat input supplied at a heater and/or an expansion cylinder of the engine and rejected heat at a cooler and/or a compression cylinder become minimum. To develop the Stirling engine, it is essential to design and develop a suitable regenerator for the engine.

There are many kinds of proposed regenerator matrix materials, e.g., wire, foil, wire screen (gauze), metal felt, foamed metal. For high-performance engines, generally, stacked wires screens woven from fine wire have been used by the reason of their high heat capacity, uniform, homogeneous, and simple fabrication. On the other hand, its disadvantage is the sealing of the periphery. Also, the limited type of woven sheets is trouble for developers. The geometry and dimensions of marketed wire screens are usually standardized, and specially ordered one is very expensive. Obviously, it would be better to use a matrix material, which has not only the flexibility to design its geometry and dimensions, but also good characteristics better than wire screens.

In this study, we evaluated the newly developed M5 Mesh sheet and M7 Mesh sheet. It was made of thin metal sheet. M5 is a square hole arranged in a grid pattern; M7 is M5 with an additional groove in the square hole. Regenerator of the 3-kW Stirling engine, NS03T was equipped with mesh sheets as a matrix.

The engine with one of the mesh sheets was operated under the condition of low temperature difference of $500^{\circ} \mathrm{C}$ to $550^{\circ} \mathrm{C}$ and working fluid of helium or nitrogen. From the measuring data, the regenerator losses and pressures losses of the regenerator are calculated. Based on the results, the characteristics of the mesh sheet matrix are discussed.

\section{SPECIFICATIONS OF NS03T}

Table 1 shows the design parameters of the NS03T engine, which was one of the engines developed from 1982 to 1988 in Toshiba[1]. The heater was changed to an electric heater from the combustion type. Figure 1 shows a schematic view of the engine used for this study. Table 2 shows the NS03T engine specifications.

Table 1. Design parameters of the $3-\mathrm{kW}$ engine

\begin{tabular}{cc}
\hline \hline Items & Parameter \\
\hline Mean pressure & $3.0 \mathrm{MPa}$ \\
Max heater temp & $1023.15 \mathrm{~K}$ \\
Cooling system & Water cooling \\
Engine speed & $500-1500 \mathrm{rpm}$ \\
Max. output power & $>3 \mathrm{~kW}$ \\
Max. thermal efficiency & $32 \%$ \\
\hline \hline
\end{tabular}


Table 2. Engine specifications

\begin{tabular}{lc}
\hline \hline Items & Data \\
\hline $\begin{array}{l}\text { Type } \\
\text { Swept volume }\end{array}$ & Two piston \\
Expansion & \\
Compression & $169 \mathrm{~cm}^{3}$ \\
Volume Phase angle & $169 \mathrm{~cm}^{3}$ \\
2. Piston & 90 degrees \\
Bore x Stroke & \\
$\quad$ Expansion & \\
Compression & $82 \mathrm{~mm} \times 32 \mathrm{~mm}$ \\
3. Regenerator & $82 \mathrm{~mm} \times 32 \mathrm{~mm}$ \\
Type & \\
Dead volume & Canned \\
Matrix Outer diameter x Length & $150 \mathrm{~cm}^{3}$ \\
\hline \hline
\end{tabular}

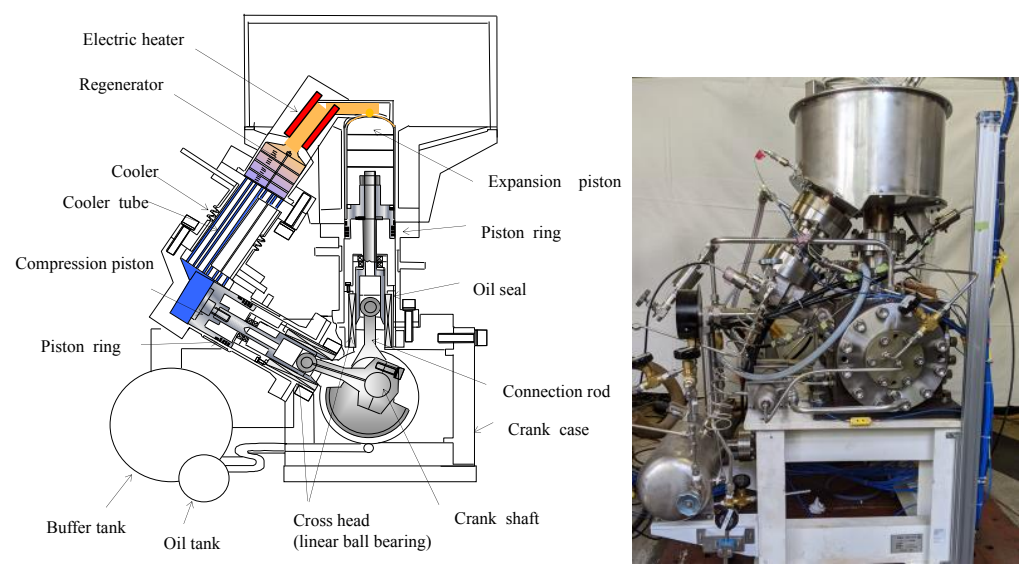

Fig. 1. NS03T engine

\section{SPECIFICATIONS OF MESH SHEET}

Figures 2, 3 and 4 show schematic views of the mesh sheets. As shown in the figures, the holes and grooves are arranged on each thin disk made of stainless steel 304. M4 is only made of nickel. Stacking M4 only was firmly bonded by a metallic surface modification after the engine operations. To avoid the bonding M4 is used in alternating layers with M3. Small square holes and shallow grooves are etched on one of the circular surfaces. The disk has a flat edge around the etched area. The precisely cut edge reduces the side leakage of the working gas. For the stainless steel rod of the matrix holder with the wheel-shaped rims, each sheet has a hole, $3 \mathrm{~mm}$ in diameter in its center.

These holes, grooves, and shape are made by an advanced etching technology. Table 3 shows the geometric parameters of the evaluated matrixes in this paper. As shown in Table 3 , these three sheets have the same pitch between the holes, but other dimensions have changed; opening width, thickness, and depth of the grooves.

In comparison, M5 is a staggered-hole mesh sheet (M1, M2, M3 and M4) with a reduced dead volume and an increased aperture ratio to reduce the flow resistance. M7 is shaped with 
steps in the stranded portion of M5 to reduce the contact area between the sheets and to reduce heat conduction loss.
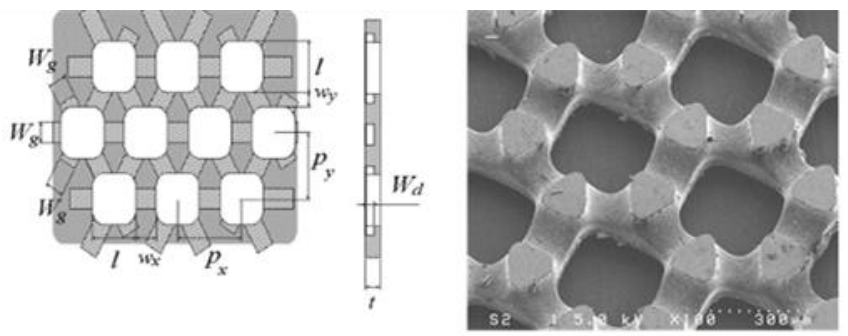

Fig. 2. Mesh sheet M1, M2, M3 and M4
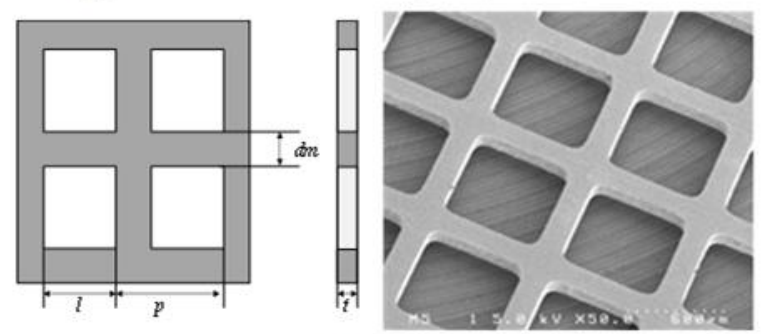

Fig. 3. Mesh sheet M5
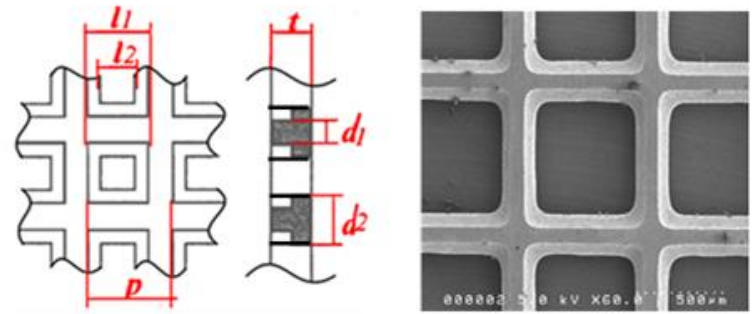

Fig. 4. Mesh sheet M7

Table 3. Geometric parameters of matrix

\begin{tabular}{|c|c|c|c|c|c|c|c|}
\hline Dimension & $\# 200$ & $\begin{array}{c}\text { M1 } \\
\text { Mesh sheet }\end{array}$ & $\begin{array}{c}\text { M2 } \\
\text { Mesh sheet }\end{array}$ & $\begin{array}{c}\text { M3 } \\
\text { Mesh sheet }\end{array}$ & $\begin{array}{c}\text { M4 } \\
\text { Mesh sheet }\end{array}$ & $\begin{array}{c}\text { M5 } \\
\text { Mesh sheet }\end{array}$ & $\begin{array}{c}\text { M7 } \\
\text { Mesh sheet }\end{array}$ \\
\hline Opening $l(\mathrm{~mm})$ & 0.066 & 0.242 & 0.280 & 0.300 & 0.300 & 0.650 & $\begin{array}{l}l_{1}: 0.680 \\
l_{2}: 0.580\end{array}$ \\
\hline Diameter $d_{m}(\mathrm{~mm})$ & 0.061 & -- & -- & -- & -- & 0.150 & $\begin{array}{l}d_{1}: 0.100 \\
d_{2}: 0.200\end{array}$ \\
\hline Width of frame (mm) & -- & $\begin{array}{l}w_{x}: 0.199 \\
w y: 0.140\end{array}$ & $\begin{array}{l}w_{x}: 0.161 \\
w_{y}: 0.102\end{array}$ & $\begin{array}{l}w_{x}: 0.141 \\
w_{y}: 0.082\end{array}$ & $\begin{array}{l}\mathrm{w}_{\mathrm{x}}: 0.141 \\
\mathrm{wy}: 0.082\end{array}$ & --. & -- \\
\hline Pitch $p(\mathrm{~mm})$ & 0.127 & $\begin{array}{l}p_{x}: 0.441 \\
p_{y}: 0.382\end{array}$ & $\begin{array}{l}p_{x}: 0.441 \\
p_{y}: 0.382\end{array}$ & $\begin{array}{l}\mathrm{p}_{\mathrm{x}}: 0.441 \\
\mathrm{p}_{\mathrm{y}}: 0.382\end{array}$ & $\begin{array}{l}p_{\mathrm{x}}: 0.441 \\
\mathrm{p}_{\mathrm{y}}: 0.382\end{array}$ & 0.800 & 0.800 \\
\hline Groove $w \mathrm{~g} \times d g(\mathrm{~mm})$ & ... & $0.120 \times 0.060$ & $.120 \times 0.060$ & $0.150 \times 0.072$ & $140 \times 0.060$ & ... & ... \\
\hline Thickness $t(\mathrm{~mm})$ & 0.122 & 0.100 & 0.100 & 0.120 & 0.100 & 0.100 & 0.100 \\
\hline Open area ratio $\beta$ & 0.270 & 0.315 & 0.433 & 0.487 & 0.502 & 0.660 & 0.738 \\
\hline Porosity $\phi$ & 0.582 & 0.543 & 0.606 & 0.667 & 0.668 & 0.660 & 0.738 \\
\hline Specific surface area $\sigma\left(\mathrm{mm}^{-1}\right)$ & 21.502 & 21.058 & 17.990 & 14.487 & 16.141 & 10.859 & 13.084 \\
\hline
\end{tabular}

\section{ENGINE PERFORMANCE}

The engine with the new matrix was driven and its performance was measured.

Thermocouples, pressure transducers, and crank-angle pickup sensors were attached to the engine. The output power was measured by a dynamometer. A data logger and a digitizer converted the analog signals received from the transducers and sensors to digital signals. The data are acquired by a personal computer (PC). Calculations of the engine 
performance, a display of the results and the engine operating conditions, and acquisition and saving of the data are automatically carried out by a software written with a graphical programming language. Table 4 describes the definitions of the powers, heats, losses, and efficiencies. $\Delta W_{p}$ means difference between a calculated $W_{\text {ind }}$ in the case of no pressure losses and the actual $W_{\text {ind }}$. Effective heat input, and $Q_{\text {rloss }}$ are derived from heat fluxes in the engine ${ }^{1}$. The typical operating conditions are arranged in Table 5.

Table 4. Definitions of powers and efficiencies

\begin{tabular}{|c|c|}
\hline $\begin{array}{l}\text { Items } \\
\text { 1.Power }\end{array}$ & Equations \\
\hline Expansion work (power) & $W_{e}=n \oint P_{e} d V_{e}$ \\
\hline Compression work (power) & $W_{c}=n \oint P_{c} d V_{c}$ \\
\hline Indicated work (power) & $W_{\text {ind }}=W_{e}-W_{c}$ \\
\hline Pressure loss & $\Delta W_{p}=\left(\oint P_{e} d V_{c}+\oint P_{c} d V_{e}-W_{\text {ind }}\right) / 2$ \\
\hline \multicolumn{2}{|l|}{ 2.Quantity of heat } \\
\hline Cooling heat in cooler (quantity) & $Q_{c}$ \\
\hline $\begin{array}{l}\text { Cooling heat in comp. cyl. water jack } \\
\text { (quantity) }\end{array}$ & $Q_{c c}$ \\
\hline Regenerator loss & $Q_{r l o s s}=Q_{c c}-W_{c}$ \\
\hline Effective heat input & $Q_{\text {eff }}=Q_{\text {rloss }}+W_{e}$ \\
\hline \multicolumn{2}{|l|}{ 3.Efficiency } \\
\hline Indicated efficiency & $\eta_{\text {ind }}=W_{\text {ind }} / Q_{\text {eff }}$ \\
\hline \multicolumn{2}{|l|}{ 4.Friction loss } \\
\hline Friction coefficient & $f_{l}=\frac{\Delta P}{\frac{1}{2} \rho u^{2} N}$ \\
\hline Pressure loss & $\Delta P=\frac{\Delta W_{p} \cdot \rho}{w_{i}}$ \\
\hline Reynolds number & $R e_{l}=\frac{l \cdot u_{l}}{v}$ \\
\hline \multicolumn{2}{|l|}{ 5.Heat transfer } \\
\hline Number of transfer units & $N_{t u}=\frac{2 w c_{p}\left(T_{r h}-T_{r l}\right)}{Q_{r l o s s}}-2$ \\
\hline Average heat transfer coefficient & $\alpha=\frac{w c_{p} N_{t u}}{S}$ \\
\hline Nusselt number & $N u_{d}=\frac{d_{m} \alpha}{\lambda}$ \\
\hline Reynolds number & $\frac{l \cdot u_{d}}{v}$ \\
\hline
\end{tabular}

Table 5. Operating conditions

\begin{tabular}{lc}
\hline \hline Items & Parameter \\
\hline Working fluid & Helium, Nitrogen \\
Mean pressure & $2.0,2.5 \mathrm{MPa}$ \\
Engine speed & $500-1500 \mathrm{rpm}$ \\
Heater temp. & $773-823 \mathrm{~K}$ \\
Compression space temp. & $283-293 \mathrm{~K}$ (water cooling) \\
\hline \hline
\end{tabular}




\section{Power}

The indicated power, $W_{\text {ind }}$ figures are shown in Figures 5, 6 and 7. In the figures, the data series are fitted with curves to clarify the behaviors. Nitrogen shows high $W_{\text {ind }}$ at $700 \mathrm{rpm}$ wiht M5 , $800 \mathrm{rpm}$ with M3+M4 and M7. Above $900 \mathrm{rpm}$, helium shows the higher $W_{\text {ind }}$. Maximum $W_{\text {ind }}$ was $948 \mathrm{~W}$ at with M3+M4, which was $51 \mathrm{~W}$ bigger than M5 and $4 \mathrm{~W}$ bigger than M7.

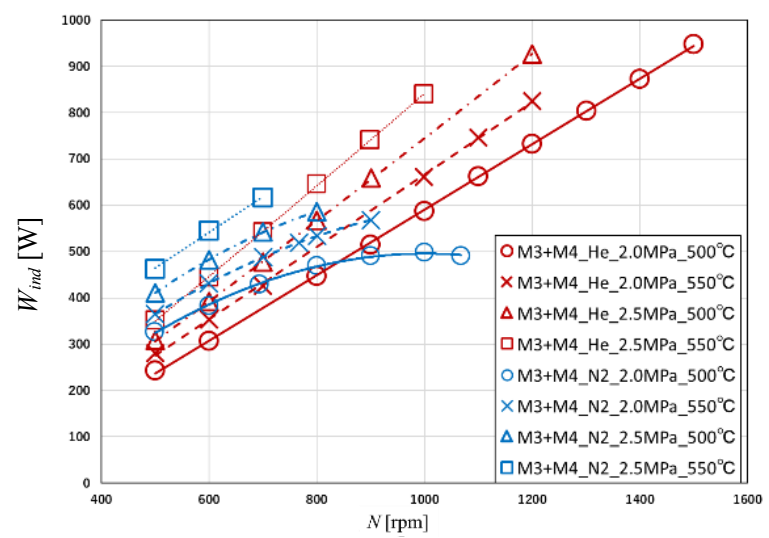

Fig. 5. Indicated power with M3+M4 Mesh sheet

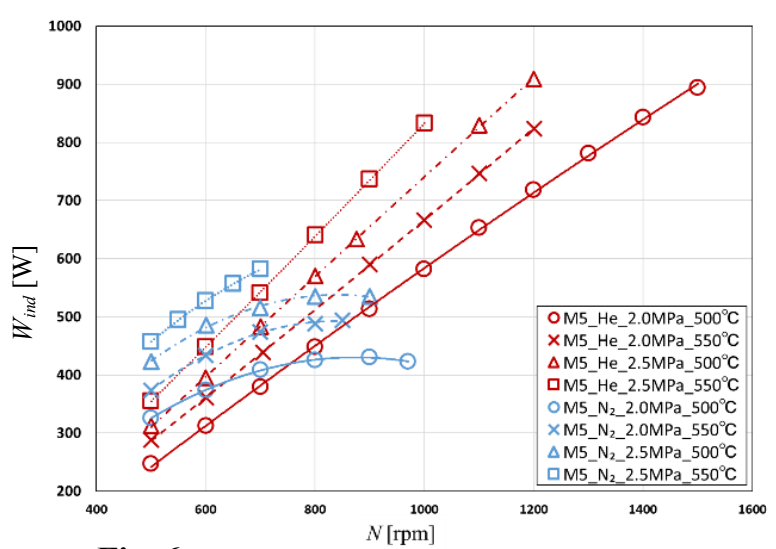

Fig. 6. Indicated power with M5 Mesh sheet

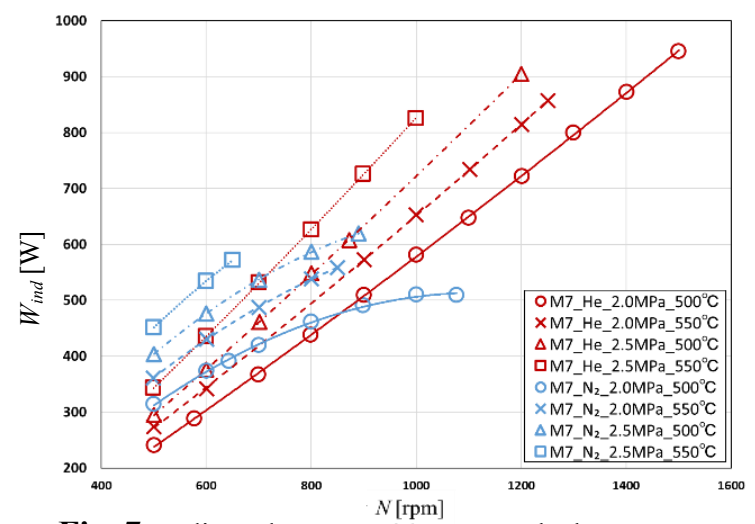

Fig. 7. Indicated power with M7 Mesh sheet 


\section{Efficiencies}

The Indicated efficiency, $\eta_{\text {ind }}$ are shown in Figures 8, 9 and 10 for M3+M4, M5 and M7. The $\eta_{\text {ind }}$ of nitrogen is bigger than that of helium when the speed is below $700 \mathrm{rpm}$. $\eta_{\text {ind }}$ of nitrogen decreases above $700 \mathrm{rpm}$ and is high under the operation using helium. The maximum $\eta_{\text {ind }}$ was $31 \%$ with M3+M4, $30 \%$ with M5, and $31 \%$ with M7.

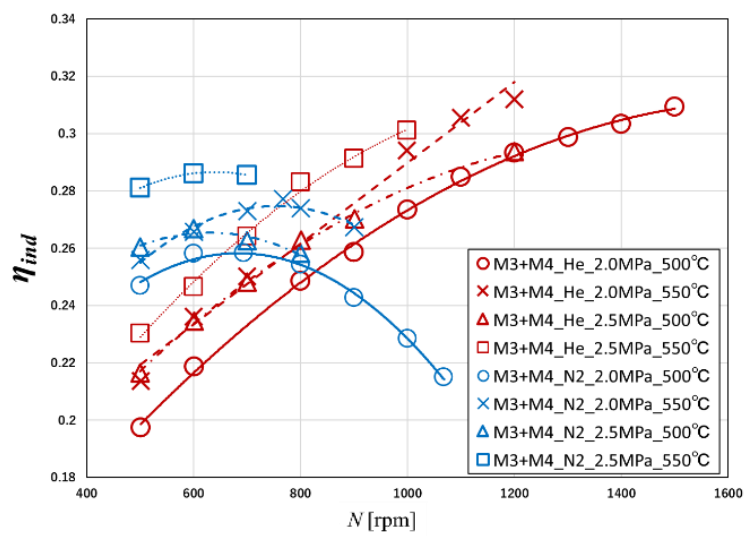

Fig. 8. Indicated efficiency in M3+M4 Mesh sheet

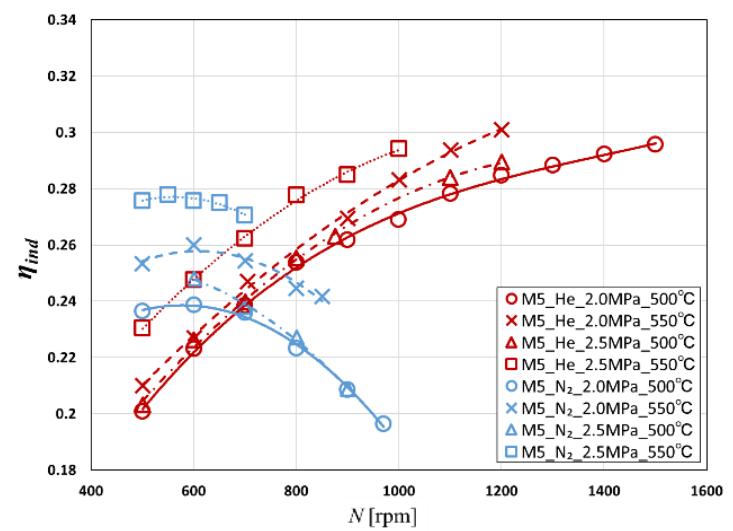

Fig. 9. Indicated efficiency in M5 Mesh sheet

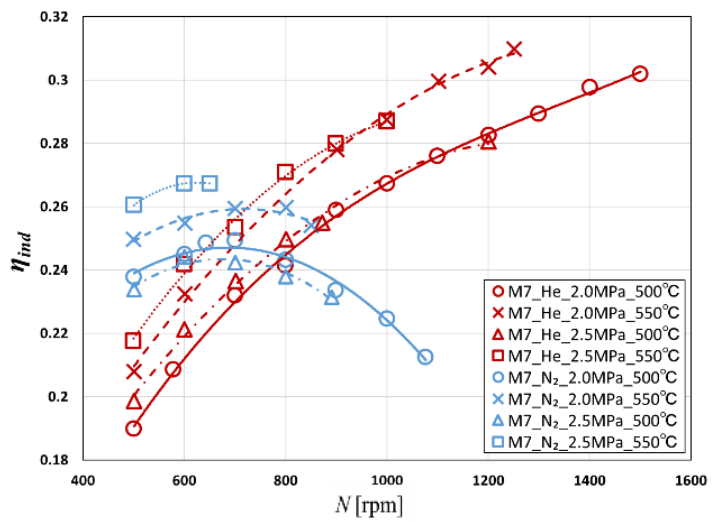

Fig. 10. Indicated efficiency with M7 Mesh sheet 


\section{Pressure loss}

The pressure loss, $\Delta W_{p}$ is shown in Figures 11,12 and 13. This loss is caused by a frictional resistance in the heat exchangers, including the heater, the cooler, and the regenerator. The loss reduces $W_{\text {ind }}$ directly. For both M5 and M7, nitrogen has a higher pressure drop than helium, and the pressure drop tends to be higher at $500{ }^{\circ} \mathrm{C}$ and $2.5 \mathrm{MPa}$. It seems that high pressure and low temperature increase the density of the working fluid and increase the fluid friction in the matrix. The $\Delta W_{p}$ of M7 tends to decrease compared to $\mathrm{M} 3+\mathrm{M} 4$ and M5.

M3+M4 and M5 were bigger than M7 by $34 \mathrm{~W}$ and $80 \mathrm{~W}$ for nitrogen and $60 \mathrm{~W}$ and 105 $\mathrm{W}$ for helium.

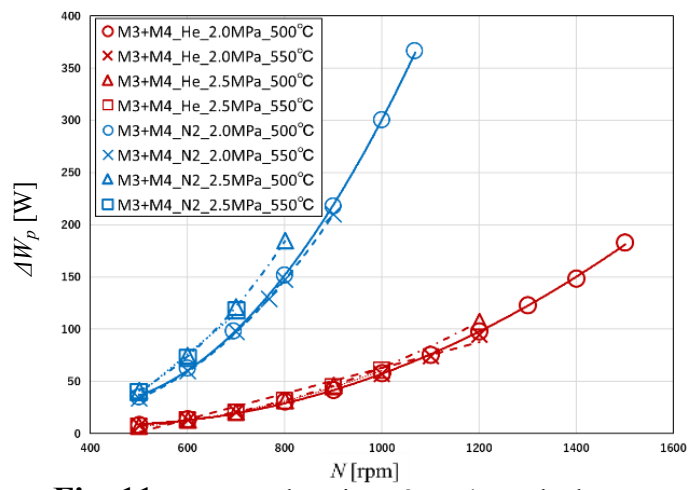

Fig. 11. Pressure loss in M3+M4 Mesh sheet

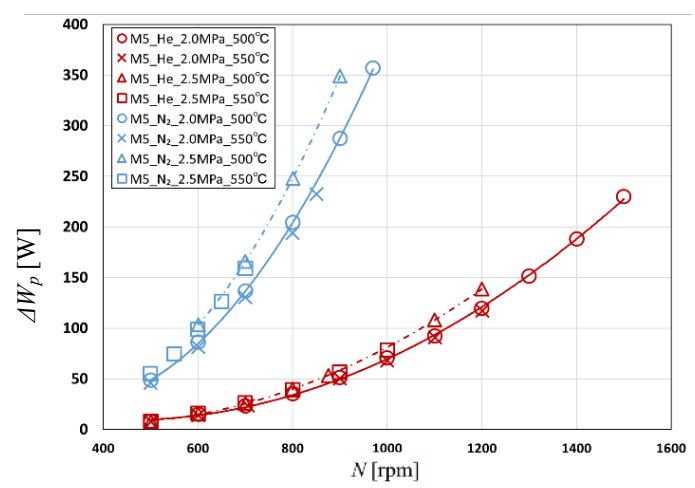

Fig. 12. Pressure loss in M5 Mesh sheet

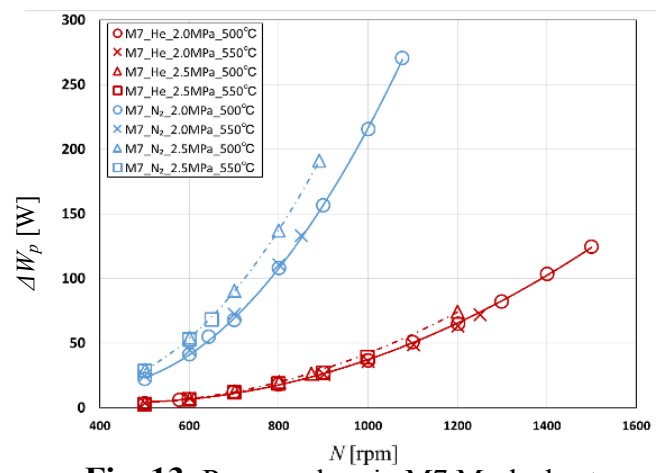

Fig. 13. Pressure loss in M7 Mesh sheet 


\section{$\underline{\text { Regenerator loss }}$}

The Regenerator loss, $Q_{\text {rloss }}$ is show in Figures 14, 15 and 16. $Q_{\text {rloss }}$, which includes the reheat and thermal conduction losses, are calculated from the quantities of the rejected heat from the cooler, the cooling heat at the water jacket of the compression cylinder, and the compression power. Therefore, the derived data have some uncertainty and scatter in the figures. Helium has a high thermal conductivity, has a lower $Q_{r l o s s}$ than nitrogen. M7 with nitrogen was $400 \mathrm{~W}$ larger than M5 with nitrogen.

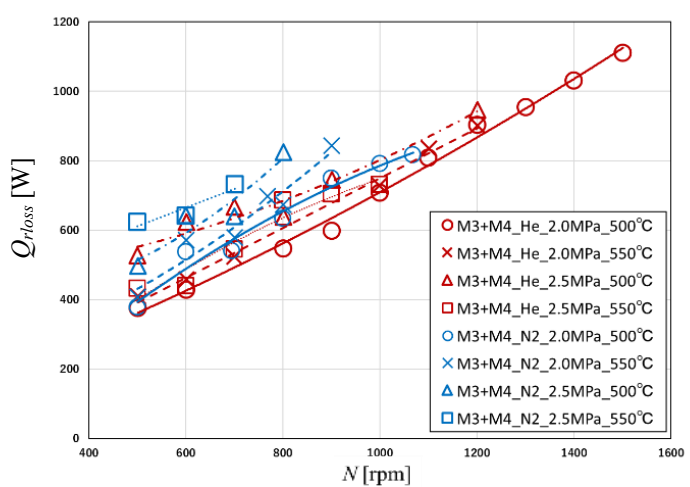

Fig. 14. Regenerator losses in M3+M4 Mesh sheet

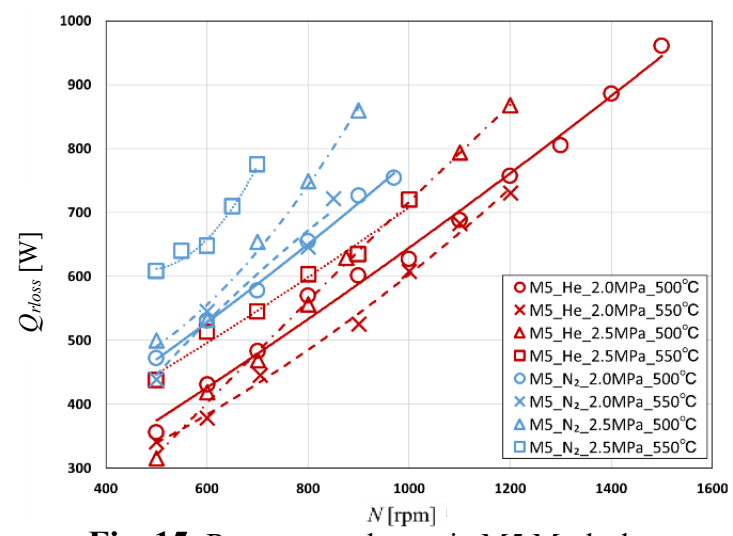

Fig. 15. Regenerator losses in M5 Mesh sheet

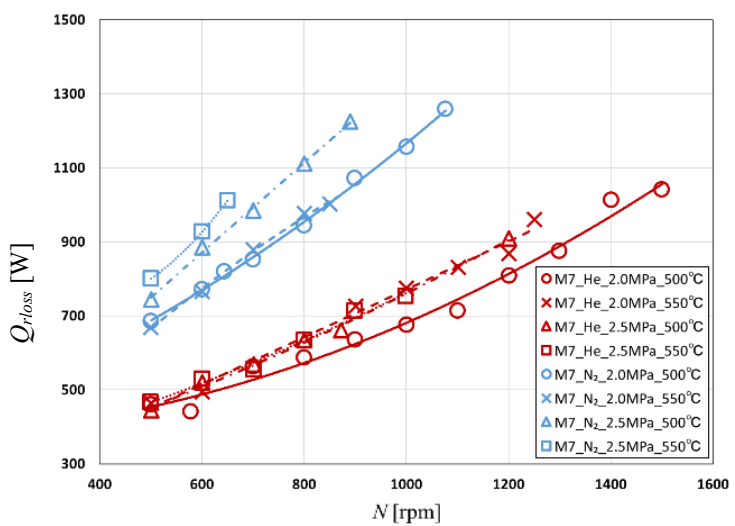

Fig. 16. Regenerator losses in M7 Mesh sheet 


\section{Friction coefficient}

The friction coefficient, $f$ is show in Figure 17.\#200, M1, and M2 are obtained from the results of previous research by Kitahama[2]. The pressure loss, $\triangle P$ caused by the flow loss in the regenerator is converted to a friction factor, $f$ and evaluated as a function of the Reynolds number, Re. The experimental equation of Tanaka[3] for unsteady reciprocating flow is also shown.

M7 is low friction coefficient and shows characteristics similar to \#200 and M3+M4. The M5 is a higher friction coefficient than the M7.

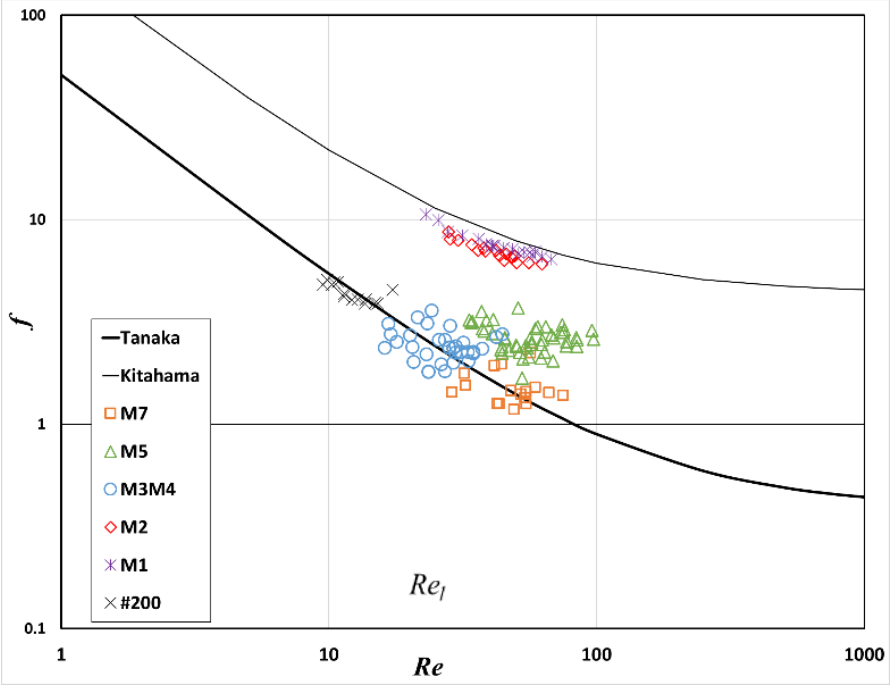

Fig. 17. Friction coefficient with $R e$

\section{Nusselt number}

The Nusselt number, $N u$ is show in Figure 18. The heat transfer characteristics of the regenerator are evaluated by the relationship between $N u$ and $R e$. M7 tends to be the same as \#200 and M1. M5 had a higher Nusselt number than M7.

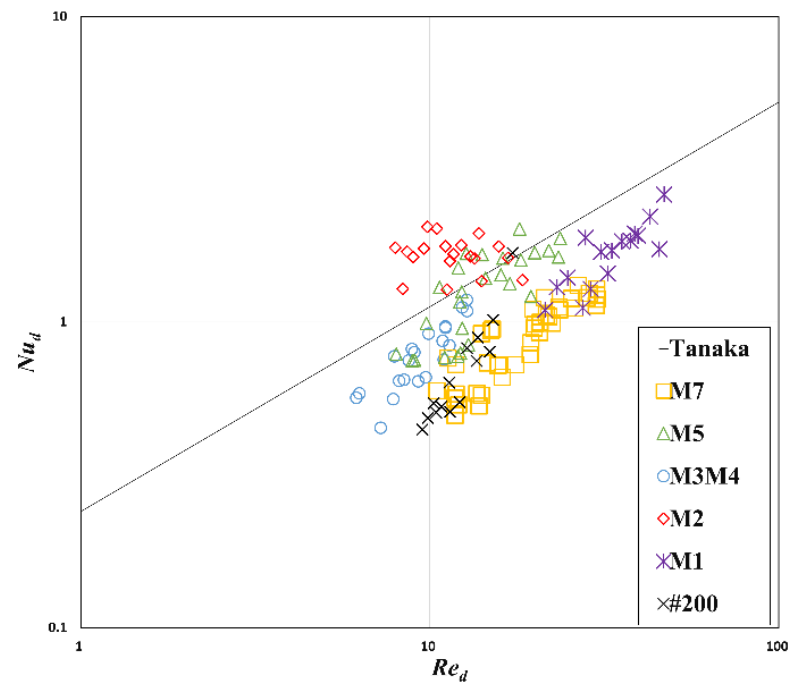

Fig. 18. Nusselt number with $R e$ 


\section{CONCLUSIONS}

In this paper, the performances of the new mesh sheet for regenerator were presented. Three types of the mesh sheet were manufactured, and were installed in the NS03T. The engine performances with the mesh sheets were measured.

Maximum $W_{\text {ind }}$ of M3+M4, M5 and M7 are $948 \mathrm{~W}, 909 \mathrm{~W}$ and $944 \mathrm{~W}$. And Maximum $\eta_{\text {ind }}$ of M3+M4, M5 and M7 are $0.312,0.301$ and $0.310 . W_{\text {ind }}$ of M7 is $6 \%$ higher than M5 and $\eta i_{n d}$ of M7 is $3 \%$ higher than M5. This is due to M7 has a smaller diameter $d m$ than M5.

$Q_{\text {rloss }}$ of M7 with nitrogen was $400 \mathrm{~W}$ larger than M5 with nitrogen. This is because the $d m$ of M7 was smaller M5. Smaller $d m$ decrease heat regeneration.

Nitrogen has higher values of both $W_{\text {ind }}$ and $\eta_{\text {ind }}$ than Helium below $700 \mathrm{rpm}$. However, Pressure loss is considered to be larger due to the size of nitrogen atom, Pressure loss is considered to be larger. It becomes clear that a suitable mesh sheet with a smaller $f$ likes $\mathrm{M} 3+\mathrm{M} 4$ and M7 is required to increase the engine power especially for changing nitrogen.

\section{ACKNOWLEDGEMENTS}

The authors acknowledge Mr. Kennichi Tamura of Japan Defense Foundation for Mutual Aid.

\section{REFERENCES}

1. Kagawa, N., Sakamoto, M., Nagatomo, S., Komakine, T., Hisoka, S., Sakuma, T., Arai, Y., and Okuda, M., Development of a $3 \mathrm{~kW}$ Stirling Engine for a Residential Heat Pump System, Proc. $4^{\text {th }}$ Int. Conference Stirling Engines, Japan Society of Mechanical Engineers, Tokyo, pp. 1-6.(1988)

2. Kitahama, D., Takizawa, H., Tsuruno, S., Sawahata, Y., Matsuguchi, A., Kagawa, N., Performance of New Matrix for Stirling Engine Regenerator, The $6^{\text {th }}$ symposium on Stirling Cycle, Japan Society of Mechanical Engineers, Tsukuba, pp. 70-74, in Japan.

3. Tanaka, M., Yamasita, I., Chisaka, F,. Flow and Heat Transfer Characteristics of Stirling Engine Regenerator in Oscillating Flow, Transactions of the Japan Society of Mechanical Engineers. Series B., pp. 2478-2485(1989) 